\title{
Research Paper: Effect of Training of Life Skills on Social Skills of High School Students With Intellectual Disabilities

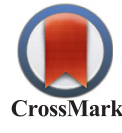

\author{
Saiedeh Behroz-Sarcheshmeh ${ }^{1}$, Masoud Karimi ${ }^{1}$, Farideh Mahmoudi ${ }^{1}$, Parvaneh Shaghaghi ${ }^{1}$, Seyyedeh Somayyeh Jalil-Abkenar ${ }^{*}$ \\ 1. Department of Psychology, Varamin-Pishva Branch, Islamic Azad University, Varamin, Iran. \\ 2. Department of Psychology and Education of Exceptional Children, Faculty of Psychology and Education, University of Tehran, Tehran, Iran.
}

\begin{tabular}{|c|c|}
\hline $\begin{array}{l}\text { Use your device to scan } \\
\text { and read the article online }\end{array}$ & Citation: Behroz-Sarcheshmeh, S., Karimi, M., Mahmoudi, F., Shaghaghi, P., \& Jalil-Abkenar, S. S. Effect of Training of Life \\
\hline 口外神回 & Skills on Social Skills of High School Students With Intellectual Disabilities. Journal of Practice in Clinical Psychology, 5(3), \\
\hline 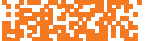 & 177-186. https://doi.org/10.18869/acadpub.jpcp.5.3.177 \\
\hline (1) & dol: $:$ https://doi.org/10.18869/acadpub.jpcp.5.3.177 \\
\hline
\end{tabular}

\section{Article info:}

Received: 25 Dec. 2016

Accepted: 20 Apr. 2017
Keywords:

Life skills, Social skills, Intellectual disabilities

\begin{abstract}
Objective: In this study, we planned to investigate the effectiveness of life skills training on the social skills of students with intellectual disabilities.

Methods: In this experimental study, with pretest and posttest design and control group, an equal number of participants was randomly assigned to experimental and control group. Life skills training were provided to experimental group $(n=20)$ in nine sessions, whereas control group was in neutral state. The teacher completed the pretest and posttest Social Skills Rating Scale (Teacher Form) for the participants. The data were analyzed by multivariate analysis of covariance (MANCOVA) using SPSS software.
\end{abstract}

Results: The results of MANCOVA revealed a significant difference between total social skills and subscales of the test (cooperation, assertiveness, and self-control) in the experimental group $(\mathrm{P}<0.005)$, whereas there was no significant difference in the control group. It is important that educators and parents reinforce learning of social skills through direct and indirect life skills training procedure.

Conclusion: The results of this study support the effectiveness of life skills training including cooperation, assertion, and self-control on social skills of high school students with intellectual disabilities.

\section{Introduction}

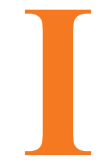

ntellectual disability can be diagnosed even before the age of 18 years, primarily characterized by significant limitations in intellectual functioning and adaptive behaviors as expressed in social, conceptual, and practical adaptive skills (American Psychiatric Association, 2013). In order to meet the needs of these children using special education, specific behaviors have to be taught in three areas. Because of the recent modification in leg- islation, research-based programs specifically designed for children with intellectual disabilities are being developed. Therefore, non-academic behaviors such as daily living and social skills have not received enough attention (Hallahan, Kauffman, \& Pullen, 2015).

Social skills can be defined as skills that allow each child to interact with others successfully. Sometimes individuals with a disability have behaviors that are unacceptable in social relationships. The inappropriate social skills can be a characteristic of their disability. Children

\section{* Corresponding Author:}

Seyyedeh Somayyeh Jalil-Abkenar, PhD

Address: Department of Psychology and Education of Exceptional Children, Faculty of Psychology and Education, University of Tehran, Tehran, Iran. Tel: +98 (912) 7918424

E-mail:jalili.abkenar@gmail.com 
may lack a specific social skill, may apply an inappropriate social skill to a specific situation, or may not be aware that a specific situation calls for a specific skill set (Akhmetzyanova, 2014).

Social skills and life skills program for children with intellectual disability can be divided into the areas of academic and non-academic program. Social skills training would be considered non-academic program. Usually, the emphasis on training with respect to social behaviors has been overshadowed by academic program (Kolb \& Hanley-Maxwell, 2003). Similar to other skills, training with respect to social behaviors must be deliberately provided and such skills must be taught and made to practice within their natural settings and the environment in which they will grow up (Hallahan \& Kauffman, 2000). By providing training in social skills, children with intellectual disability can learn to get along with others and adapt to various social conditions (Akhmetzyanova, 2014).

Many studies have proven that inappropriate social skills are an important element contributing to the failure of individuals with intellectual disability in community placements (Paraschiv \& Oiley, 1999). In addition, social learning theory by Albert Bandura can be applied to the development of social skills in children with intellectual disabilities. Social learning emphasizes the importance of observation and subsequent modeling of attitudes, behaviors, and emotional reactions of others. Bandura's theory is also based on the premise that social relationships play a main role in the cognitive development of individuals (Heller, Hsieh, \& Rimmer, 2006).

Based on the need of youth and changes in the society, the education system and curricula in Iran have been reformed in the past two decades. The current education system in Iran strives to provide students to challenge their everyday life based on the program and curriculum, for which greater emphasis has been placed in the past few years such as life skills training (Iran Chapter Society (ICS), 2001). However, it is worth mentioning that life skill training also plays an important role in Iran's educational system at the secondary level. Education of Islamic life skills is a set of skills required for living in Islamic society. These skills are based on peoples' observation and response to the values and norms of society and individual needs, which enable students to confront and solve their problems by using religious teachings (Katherine Quigley, 2007).

Many problems, such as health and social problems, the big concern of the third millennium, is increasing day-by-day. Incidence of such problems in Islamic Re- public (IR) of Iran has shifted from low level to concentrated levels (Report of Ministry of Health, Treatment \& Medical Education, 2006, cited in Ministry of Education of the IR of Iran, 2008). The first serious discussions and analyses of life skills emerged by Botvin in 1979. This approach aims to assist young people to regain control over their behavior while taking informed decisions that can lead to positive behaviors and values. In addition, it can provide opportunities to students to practice interpersonal skills by using interactive education and learning methods (Adewale, 2011). This type of education aids students to enhance their social and personal development and to prevent social and health problems and also helps in the protection of human rights (WHO, 1993).

Botvin, Baker, Dusenbury and Tortu (1990), Botvin and Kantor (2000), and Botvin, Griffin, Paul and Macaulay (2003) have developed a life skills training program to prevent substance abuse for middle and junior high school students. Such life skills training programs have demonstrated immediate and dramatic positive effects on children, youth, and adults in some countries. Studies related to life skills domain have suggested that some abilities that help children or adolescents to promote their health and well-being should be considered as the heart of skill-based initiatives.

Some of the life skills that have been given special attention in education system for both primary and secondary levels are effective communication, self-awareness, empathy, decision making, interpersonal relationship, creative thinking, problem-solving, critical thinking, coping with stress, and coping with emotions (WHO, 2013; Mangrulkar, Whitman, \& Posner, 2001; KordNoghabi \& Pasha Sharifii, 2008). Life skills programs effectively teach skills that help to enhance personal and social competencies (Botvin \& Griffin, 2004). According to Botvin (2002), training of life skills program can decrease behaviors that might be risky for students (Botvin, 2002). Katherine Quigley (2007) conducted the effectiveness of life skills training on the personal and social skills scores of rural high school students with intellectual disabilities. The study measured improvements made in the personal-social skills of students as measured by pretest and posttest scores of the life skills program and competency rating scale.

The results showed that the students in the experimental group showed a greater increase in scores on the competency rating scale than that of students that belonged to the control group. Lou, Wang, Tu and Gao (2008) postulated that young people can increase their capability with the help of these skills and thus, they can make healthier 
choices, resisting negative pressures, and avoiding risky behaviors. Therefore, life skills should be taught at all levels and all ages of students (Economic and Social Commission for Asia and the Pacific, 2009).

Several attempts have been made to incorporate training in life skills in the education system. For instance, the Armenian education system conducted life skills training program as a component of an overall effort in education modification (Ministry of Education and Science of Armenia, 2001). Iceland Ministry of Education, Science, and Culture provided life skills training to encourage students' all-round development in order to enable them to better deal with the challenges and demands of everyday life (Ministry of Education of Iceland, 2004). Ministry of Education and Training in Vietnam (2006) conducted life skills training by referring to individual's ability (knowledge, values, attitude, and skills) to perform life functions and to fully participate in daily life. Sharma (2003) used a survey to assess the level of life skills in adolescents of a secondary school at Katmandu. He, based on WHO's definition, prepared a questionnaire in English with several questions to test life skills of students. According to his findings, 51\% adolescents had a higher level of life skills. In addition, another interesting result related to life skills' awareness of teachers revealed that according to them, life skills is same as vocational training and livelihood skills.

In this study, we focused on the social competency as in independence, socially acceptable behavior, selfconfidence, and maintenance of friendships for children with intellectual disability. The primary factors that were included in training were acquiring self-confidence, achieving socially responsible behavior, achieving self-awareness, maintaining good interpersonal skills, achieving problem-solving skills, achieving independence, and communicating with others. Instructions for social skills were typically the primary aspect of programs for individuals with intellectual disability (Hallahan et al., 2015). It is essential that children initiate and maintain desirable social interactions with their peers, family, teachers, and people within their community. "Social skills are defined as a complex set of behaviors that include problem-solving and decision-making, communication, assertion, self-management and peer and group interactions" (Kirk, Gallagher, \& Coleman, 2015).

Most students learn social skills from interaction with other children, friends, and family members. Some students with intellectual disability will need to learn social behaviors and skills more directly. This may include the use of a specific program and the use of individualized methods. Further studies are needed in this regard; however, to confirm our existing findings and to extend our knowledge base, we need to pay attention to improving social skills for students with intellectual disabled. The primary purpose of this research was to determine the effectiveness of life skills training on social skills of high school students with intellectual disability.

\section{Methods}

This is an experimental study with pretest and posttest design and a control group. Sample includes 40 high school boy students with intellectual disabilities between 16 and 18 years of age who had enrolled in public schools in Tehran during the academic year 2011-2012. Tehran is the capital of Iran. There are eight high schools in Tehran. Participants were selected by random sampling technique. From the list of schools, two schools were randomly selected. Participants were selected randomly from these two schools and were divided into two groups randomly (experimental and control group), each of which consisted of 20 students. Because of the employed semi-experimental method, the minimum required sample size was 15 for each group. Sample size was determined as 17 subjects based on the given formula. However, the sample size was determined as 20 subjects because of the possibility of dropout of the subjects during the study. However, the obtained results should be generalized cautiously.

$$
n=\frac{\sigma^{2}\left(z_{1}-a / 2\right)^{2}}{d^{2}}=(22.98)^{2} \times(1.96)^{2} /(11)^{2}=16.76
$$

Inclusion criteria consisted of students aged between 16 and 18 years, $10^{\text {th }}$ to $12^{\text {th }}$ school grade, and living with parents. Participants were excluded from the study if there was evidence of developmental disorders or significant health impairment except for intellectual disabilities, and who are not currently enrolled in a similar training program. The Ethics Committee of Exceptional Education Organization in Iran approved this study. The importance of research was explained to the schools principals, counselors, and participants, ensuring that all participants would be protected against any probable harm. Informed consent was also obtained from parents of participants.

Assigning the names of experimental and control into the groups was performed randomly by drawing. In this method, the names of experimental and control groups were written on the slips of a paper. Then, the slips were withdrawn from a container as a lottery. The experimental group received life skill training in nine sessions, whereas control group did not receive any training. Prior to the intervention, research procedure was explained 
to the school authorities and informed consent was obtained from all the parents of students. The instruments of this research were Social Skills Rating Scale (SSRS) and life skill program.

SSRS was developed by Frank Gresham and Stephen Elliot in 1990. This scale has three forms: a teacher form (SSRS-T), a parent form (SSRS-P), and a student form (SSRS-S). SSRS-T was used in this study (Shoemaker, 2009). This form measures responses of three subscales: cooperation, assertion, and self-control. "Cooperation" subscale assesses behaviors such as helping others, sharing materials, and complying with rules and directions. "Assertion" subscale assesses initiating behaviors such as asking others for information, introducing oneself, and responding to the actions of others. "Self-control" subscale measures behaviors that emerge during situations of conflict, such as responding appropriately to assessing, and in nonconflict situations that require taking turns and compromising (Van der Oorda et al, 2005).

SSRS is a 30 -item measure with three subscales and 10 items each. A total score can range from 0 to 60 . SSRS-T is rated on a 3-point Likert scale ranging from 0 (never) to 2 (often). Higher scores indicate better social skills and lower scores indicate impairment in social skills. Internal consistencies of SSRS are satisfactory. The internal consistency of SSRS subscales ranged from 0.51 to 0.91 , with a mean internal consistency of 0.75 (Gresham \& Elliot, 1990). Furthermore, Shahim (1999) has found high alpha coefficients (0.92) for the teacher versions Studies examining convergent validity have moderate to high correlations among the SSRS and other social competence instruments, including the Woodcock-Johnson Scales of Independent Behavior (Merrell \& Popinga, 1994), the Vineland Adaptive Behavior Scales (Lyon, Albertus, Birkinbine, \& Naibi, 1996), and the Behavior Assessment System for Children (BASC) (Flanagan, Alfonso, Primavera, Povall, Higgins, 1996). Flanagan et al. (1996) found a high positive and significant correlation between parent ratings on the BASC and the SSRS $(\mathrm{r}=0.58)$. However, teacher ratings indicated that a low correlation between the SSRS and the BASC $(r=0.23)$. The internal validities of the cooperation, assertion, and self-control subscales have been calculated by Cronbach's alpha and were $0.79,0.63$, and 0.88 , respectively.

The intervention training program used in this study is life skills program (World Health Organization, 1993). This program includes a catalog of skills (Table 1). Experimental group received life skill training in nine sessions (two 50-min sessions a week), whereas control group did not receive any training. There was no contact between members of the research team and sample subjects during this period. The teacher completed the SSRS-T Form for the subjects at pretest and posttest. Outcome measures were obtained at pretest and posttest from each group. The data were analyzed by multivariate analysis of covariance (version 19, SPSS Inc., Chicago, IL).

Table 1. Description of items in the life skill program

\begin{tabular}{|c|c|c|}
\hline Skills & Sessions & Context of Program in Each Session \\
\hline ----- & 1 & Familiarization with life skill program and goals \\
\hline \multirow{2}{*}{ Self-development } & 2 & $\begin{array}{l}\text { Identify of positive characteristics of the students, Diagnosis between misunderstanding } \\
\text { and making a mistake }\end{array}$ \\
\hline & 3 & $\begin{array}{c}\text { Identifying of desirable or not desirable characteristics, Development and change percep- } \\
\text { tion in the life span }\end{array}$ \\
\hline \multirow{3}{*}{ Emotional-development } & 4 & $\begin{array}{l}\text { Rejected perception and loneliness on others, Effective methods of coping with rejection } \\
\text { and loneliness, Role of self in sensation assertion }\end{array}$ \\
\hline & & \\
\hline & 5 & $\begin{array}{l}\text { Identifying unfavorable emotions, Effective methods of adjustment with emotions, Toler- } \\
\text { ance of rejection and loneliness }\end{array}$ \\
\hline \multirow[b]{2}{*}{ Social-development } & 6 & Cooperation and collaboration, Effective interpersonal interactions, Decision-making skills \\
\hline & 7 & $\begin{array}{l}\text { Effective skills in the conflict management, Identifying rejection and loneliness causes, } \\
\text { External word thinking of other perspective }\end{array}$ \\
\hline \multirow{2}{*}{ Cognitive-development } & 8 & $\begin{array}{l}\text { Selections and diagnosis of each one important, Separation of reasonable belief, Attention } \\
\text { to positive and negative outcome of decisions }\end{array}$ \\
\hline & 9 & Coping with stress and emotions, Review of programs \\
\hline
\end{tabular}




\section{Results}

Average age in experimental and control groups was found to be 17.10 and 17.9 years, respectively, and average IQ was found to be 61.31 and 61.86 , respectively. The impact of program (life skill training) first determined contrasting pretest with posttest scores of SSRS-T by ANCOVA in both control and experimental groups (Table 2). ANCOVA revealed inequalities among some mean scores while taking into account the influence of the covariate. By comparing the mean scores of experimental and control groups, a linear association between the pretest and posttest scores was obtained, $\mathrm{F} 1,37=0.766, \mathrm{P}=0.090$. Furthermore, the assumption of equality-of-variances was confirmed by this analysis.

As can be seen in Table 2, the effect of covariate (pretest) was significant $(\mathrm{F} 1,37=43.884, \mathrm{P}<0.0005)$ indicating that the pretest and posttest scores were significantly correlated. Furthermore, the effect between experimental and control groups was significant, F1,37=561.894, $\mathrm{P}<0.0005$. In summary, ANCOVA demonstrated a significant difference between the means of the two groups and also showed a positive and significant effect of life skill training. Descriptive statistics were used to compare each group's scores with regard to social skills subscales (cooperation, assertion, and self-control). Table 3 shows their mean scores and standard deviation as an overall group index.

To assess SSRS in order to discriminate between children with intellectual disabilities, we conducted multivariate analysis of covariance (MANCOVA). Total score of the subscales -cooperation, assertion, and selfcontrol- were used as predictor variables. The overall Wilk's lambda was found to be significant $(F 3,33=2.190$, $\mathrm{P}=0.0005$ ) indicating that overall predictors differentiated between the two groups. In order to understand the differences among subscales scores of cooperation, assertion, and self-control skills between experimental and control groups, we performed MANCOVA test (Table 4).

We found significant differences among subscales scores of cooperation, assertion, and self-control skills between experimental and control groups $(\mathrm{P}<0.0005)$ (Table 4). According to the results of MANCOVA, life skills training had significant and positive effect on the cooperation $(\mathrm{F}=392.385, \mathrm{P}<0.0005)$, assertion $(\mathrm{F}=235.669, \mathrm{P}<0.0005)$, and self-control skills $(\mathrm{F}=157.369, \mathrm{P}<0.0005)$.

Table 2. Analysis of covariance summary

\begin{tabular}{|c|c|c|c|c|c|c|}
\hline Source of Change & SS & df & MS & $\mathbf{F}$ & Sig. & $2 \eta$ \\
\hline Pretest & 78.942 & 1 & 78.942 & 43.884 & $<0.0005$ & 0.543 \\
\hline Group & 1010.776 & 1 & 1010.776 & 561.894 & $<0.0005$ & 0.938 \\
\hline Error & 66.558 & 37 & 1.799 & & & \\
\hline Total & 1185.900 & 39 & & & & \\
\hline
\end{tabular}

Table 3. Descriptive statistics for each subscale and group (pretest \& posttest)

\begin{tabular}{cccccc}
\hline \multirow{2}{*}{ Subscales } & Situation & \multicolumn{2}{c}{ Experimental Group } & \multicolumn{2}{c}{ Control Group } \\
\cline { 3 - 6 } & & Mean & Std Deviation & Mean & Std Deviation \\
\hline \multirow{2}{*}{ Cooperation } & Pretest & 9.50 & 1.10 & 9.55 & 1.19 \\
& Posttest & 13.80 & 1.15 & 9.45 & 1.05 \\
Assertion & Pretest & 8.85 & 1.30 & 8.60 & 1.14 \\
& Posttest & 12.30 & 1.38 & 8.75 & 0.96 \\
\multirow{2}{*}{ Self-control } & Pretest & 7.45 & 1.09 & 7.45 & 1.09 \\
& Posttest & 10.10 & 0.91 & 7.60 & .99 \\
\hline
\end{tabular}


Table 4. Multivariate analysis of covariance summary

\begin{tabular}{|c|c|c|c|c|c|c|c|}
\hline Source & Depended Variable & SS & df & MS & $\mathbf{F}$ & Sig. & $2 \eta$ \\
\hline & Cooperation & 27.221 & 1 & 27.221 & 56.663 & $<0.0005$ & 0.618 \\
\hline \multirow[t]{3}{*}{ Pretest } & Assertion & 34.073 & 1 & 34.073 & 72.531 & $<0.0005$ & 0.675 \\
\hline & Self-control & 18.918 & 1 & 18.918 & 47.863 & $<0.0005$ & 0.578 \\
\hline & Cooperation & 188.498 & 1 & 188.498 & 392.385 & $<0.0005$ & 0.918 \\
\hline \multirow[t]{2}{*}{ Group } & Assertion & 110.710 & 1 & 110.710 & 235.669 & $<0.0005$ & 0.871 \\
\hline & Self-control & 62.202 & 1 & 62.202 & 157.369 & $<0.0005$ & 0.818 \\
\hline
\end{tabular}

\section{Discussion}

In this study, we aimed to investigate the effectiveness of life skills training on social skills of students with intellectual disabilities. First, we evaluated the effectiveness of life skills training at pretest and posttest on social skills of high school students with intellectual disabilities by randomly dividing students into two groups (experimental and control). Second, we evaluated the differences between experimental and control groups by examining the subscales of social skills (cooperation, assertion, and self-control) at pretest and posttest for both groups.

The results of this study support the effectiveness of life skills training on social skills of high school students with intellectual disabilities. This is in agreement with the results of Turner, McDonald and Somerset (2008) who concluded that there were significant relationships among life skills, mathematical reasoning, and critical thinking. Furthermore, our results were similar with those of Korinek and Popp (1997) who concluded that verbal and nonverbal behavior affected peer interaction and social consequence. Current research about special education relating to social skills focuses on students' participation and progress in the general education program (Hager \& Slocum, 2002). Many teachers were seeking to determine if the standard-based change was creating a program for students with intellectual disability that was more academic-oriented, resulting in less time being spent on functional behaviors (Agran, Alper, \& Wehmeyer, 2002).

The study conducted by Quintana (2004) on social skills of students with intellectual disability involved a single subject and by utilizing a A-B-A-B design and the implementation of social skills instruction program paying attention to undesirable behaviors. Results showed that there was a positive and significant effect on life skills instruction and the behavior in subjects.
We can say that although some students with intellectual disability are able to pick up desirable skills through their daily interactions with peers and parent, it is important that teachers and parents reinforce learning of social behaviors with direct and indirect life skills training. As a result of this, there was an improvement in mean scores in the experimental group; it can be assumed that over time, a life skills training program can have positive and significant effects. Consequently, a functional program supported by academic curriculum allows children with intellectual disability to utilize functional behaviors that enable them to live and work in their community (Hallahan et al., 2015). Therefore, the children's education program should include integrated life skills training program in their academic program. One such vital life skill essential for children with intellectual disabilities to be exposed to was personal skills or social behaviors.

Other studies have also showed that life skills training had a significant and positive effect on cooperation, assertion, and self-control skills. For example, Mahvashevernosfaderani, Adibsereshki and Movallali (2012) concluded that life skills training had a significant effect on cooperation, assertion, and self-control skills in case of students with hearing impairment. Furthermore, Kazemi, Momeni and Kiamarsi (2011) concluded that life skills training increased behavioral skills of students with dyscalculia. Children with intellectual disabilities experience the lack of functional skills or adaptive behaviors. However, the main content aspects were being emphasized in legislation and not the functional program that was needed for children with intellectual disabilities. Therefore, in this study, we attempted to address whether life skills instruction program positively affects the performance of children with intellectual disabilities by conducting knowledge-based assessment and a scale such as SSRS (Shoemaker, 2009). However, a functional program supported by academic curriculum allows stu- 
dents with intellectual disabilities to apply functional behaviors enabling them to live in their community. The current trend is that for children to be exposed to the general education program, preventing children from receiving vital training in non-academic skills such as social behaviors. Increases in mean scores of social skills showed that long-term extensive training could be beneficial to continue to incorporate essential functional life skills into the program for children with intellectual disabilities. In addition, a program with regard to academics and life skills could be applied to address other important issues within the special educational area. The current trends in special education indicate some issues such as participation in an outcome-based assessment process, integration, functional life skills, self-determination, and transitional services (Kirk et al, 2015).

Finally, the mandate for transitional services is a new change in special education. Transitional services include vocational instruction, postsecondary education, integrated employment, educated in adulthood, independent living, adult services, and community participation. The life skills program might help children to "learn and develop the vital skills they will need to be productive and successful upon making the transition from school to community life and work" (Ashoori, Jalilabkenar, Ashoori, Abdollahzadeh Rafi, \& Hasanzadeh Avval, 2012). In conclusion, this study demonstrated that life skills training might promote social skills of students with intellectual disabilities. Life skills training is a multilevel behavioral intervention, based on social learning principles, which aims to prevent and treat behavioral, emotional, and developmental problems in children and adolescents by enhancing their knowledge, skills, and self-concept. However, life skills training can lead to enhancement of relationships and interaction of students, planning for life skills training has particular importance. This study demonstrated the effectiveness of life skills training on social skills of high school students with intellectual disabilities. Our findings also showed that life skills training had a significant and positive effect on cooperation, assertion, and self-control skills.

This study had some limitations. First, the nature of working with an individual with intellectual disability was often inconsistent. It was partly difficult to ascertain the progress of children with intellectual disability as they frequently progress at slower rates and required additional time and training to understand important concepts. "Special education study, for its complexity, may be the hardest of the hardest-to-do sciences. One of the features of special education study that makes it more complex is the variability of the subjects" (Odom et al,
2005). Furthermore, the demographic information represented were limited attention paid to ethnicity and race of students. This limitation made it difficult to generalize the results of the research to the general population. In addition, the small sample size was a limitation. Since there were 40 subjects participating in research, findings could be difficult to relate to the other students in special education. Other limitations that are the population might impose, the time constraints of the research could also be an indicator affecting the outcomes.

Further research in this area might create many opportunities for related research. First, this study could be expanded to include a larger group of children. Furthermore, life skills training program included three additional areas focusing on the assertion, cooperation, and self-control skills, which would provide opportunities to demonstrate if improvements in these domains can be made following the implementation of the program. So, it would be beneficial to complete a longitudinal research to determine the rate of students' improvements over the course of preschool and high school as training is provided throughout their education. Finally, other studies resulting from this study could revolve around incorporating any portion of life skills program into various subjects such as children with learning disorders or emotional and behavioral disorders. Furthermore, it is better to plan the programs such as life skills program training for students with intellectual disabilities in order to increase friendly and positive relationships and promote social skills.

\section{Acknowledgments}

This research did not receive any specific grant from funding agencies in the public, commercial, or notfor-profit sectors. Authors would like to appreciate the administration for exceptional children education in Tehran. In addition, we respectfully appreciate all the children who participated in the research and all those who assisted us in the research administration.

\section{Conflict of Interest}

The authors declared no conflicts of interest.

\section{References}

Adewale, J. G. (2011). Competency level of Nigerian Primary 4 pupils in life skills achievement test. International Journal of Primary, Elementary and Early Years Education, 39(3), 221-32. doi: 10.1080/03004270903454196 
Agran, M., Alper, S., \& Wehmeyer, M. (2002). Access to the general curriculum for students with significant disabilities: What it means to teachers. Education and Training in Mental Retardation and Developmental Disabilities, 37(2), 123-33.

Akhmetzyanova, A. I. (2014). The development of self-care skills of children with severe mental retardation in the context of Lekoteka. World Applied Sciences Journal, 29(6), 724-27. doi: 10.5829/idosi.wasj.2014.29.06.13922

Lyon, M. A., Albertus, C., Birkinbine, J., \& Naibi, J. (1996). A validity study of the social skills rating system-teacher version with disabled and nondisabled preschool children. Perceptual and Motor Skills, 83(1), 307-16. doi: 10.2466/pms.1996.83.1.307

American Psychiatric Association. (2013). Diagnostic and statistical manual of mental disorders. ( $\left.5^{\text {th }} \mathrm{Ed}\right)$. Washington, D.C.: American Psychiatric Association.

American Association on Intellectual and Developmental Disabilities. (2002). Definition of Intellectual Disability [Internet]. Retrieved from http://aaidd.org/intellectual-disability/ definition\#.WXLsNISGPIV

Ashoori, M., Jalilabkenar S. S., Ashoori, J., Abdollahzadeh Rafi, M., \& Hasanzadeh Avval, M. (2012). Learning Disorders and Academic skills. (1 ${ }^{\text {st }} \mathrm{Ed}$.). Tehran: Roshd-e Farhang.

Botvin, G. J. (2002). Planning workbook, a guide for implementing. Life skills training program. New York: National Health Promotion Associated, Inc.

Botvin, G. J., Baker, E., Dusenbury, L., Tortu, S., \& Botvin, E. M. (1990). Preventing adolescent drug abuse through a multimodal cognitive-behavioral approach: Results of a 3-year study. Journal of Consulting and Clinical Psychology, 58(4), 437446. doi: 10.1037/0022-006x.58.4.437

Botvin, G. J., \& Griffin, K. W. (2004). Life skills training: empirical findings and future directions. Journal of Primary Prevention, 25(2), 211-32. doi: 10.1023/b:jopp.0000042391.58573.5b

Botvin, G. J., Griffin, K. W., Paul, E., \& Macaulay, A. P. (2003). Preventing tobacco and alcohol use among elementary school students through life skills training. Journal of Child \& Adolescent Substance Abuse, 12(4), 1-17. doi: 10.1300/j029v12n04_01

Botvin, G. J., \& Kantor, L. W. (2000). Preventing alcohol and tobacco use through life skills training. Journal of Alcohol Research and Health, 24(4), 250-7. PMID: 15986720

Brolin, D. (1997). Life centered career education: A competency based approach. Arlington: The Council for Exceptional Children.

Economic and Social Commission for Asia and the Pacific. (2009). Strengthening life skills for positive youth health behavior: An overview and discussion paper. New York: United Nations.

Flanagan, D., Alfonso, V., Primavera, L., Povall, L., Higgins, D. (1996). Convergent validity of the BASC and SSRS: Implications for social skills assessment. Psychology in the Schools, $33(1), 13-23$.

Gresham, F., \& Elliot, S. (1984). Assessment and classification of children's social skills: A review of methods and issues. Journal of School Psychology Review, 13(3), 292-301.

Gresham, F. M., \& Elliot, S. N. (1990). Social skills rating system manual. Circle Pines: American Guidance Service.
Hager, K., \& Slocum, T. (2002). Alternate assessment: No child left behind during statewide testing. Paper presented at the Annual Conference of the American Council on Rural Special Education, Reno, Nevada, 22 March 2002.

Hallahan, D., \& Kauffman, J. (2000). Exceptional learners: Introduction to special education. Boston: Allyn \& Bacon.

Hallahan, D. P., Kauffman, J. M., \& Pullen, P. C. (2015). Exceptional learners: an introduction to special education. $\left(13^{\text {th }} \mathrm{Ed}\right)$. London: Pearson.

Heller, T., Hsieh, K., \& Rimmer, J. (2006). Barriers and supports for exercise participation among adults with Down syndrome. Journal of Gerontological Social Work, 38(1-2), 161-78. doi: 10.1300/j083v38n01_03

Iran Chamber Society. (2001). The Iranian educational system, a brief review of Iranian education system. Retrieved from http:/ / www.iranchamber.com/education/articles/educational_ system.php

Katherine Quigley, M. (2007). The effects of life skills instruction on the personal-social skills scores of rural high school students with mental retardation [PhD thesis]. Lynchburg: Liberty University.

Kazemi, R., Momeni, S., \& Kiamarsi, A. (2011). [The effectiveness of life skills training on the social competence of students with dyscalculia (Persian)]. Journal of Learning Disabilities, 1(1), 94-108.

Kirk, S., Gallagher, G., \& Coleman, M. R. (2015). Educating Exceptional Children. (14 $\left.4^{\text {th }} \mathrm{Ed}\right)$. Belmont: Wadsworth Publishing.

Kolb, S. M., \& Hanley-Maxwell, C. (2003). Critical social skills for adolescents with high incidence disabilities: Parental perspectives. Exceptional Children, 69(2), 163-179. doi: $10.1177 / 001440290306900203$

Kord-Noghabi, R., \& PashSharifi, H. (2008). Preparation and compilation of a life skills curriculum for students in the high school period. Quarterly Journal of Educational Innovations, 24, 47-56.

Korinek, L., \& Popp, P. A. (1997). Collaborative mainstream in tegration of social skills with academic instruction. Prevent ing School Failure: Alternative Education for Children and Youth 41(4), 148-52. doi: 10.1080/10459889709603284

Lou, C., Wang, X., Tu, X., \& Gao, E. (2008). Impact of life skills training to improve cognition on risk of sexual behavior and contraceptive use among vocational school students in Shanghai, China. Journal of Reproduction and Contraception, 19(4), 239-51. doi: 10.1016/s1001-7844(08)60026-7

Mahvashevernosfaderani, A., Adibsereshki, N., \& Movallali, G. (2012). [The effectiveness of life skills training on enhancing the social skills of hearing impaired boy secondary school students in inclusive schools (Persian)]. Journal of Research on Rehabilitation Science, 8(3), 477-88.

Mangrulkar, L., Whitman, C. V., \& Posner, M. (2001). Life skills approach to child and adolescent healthy human development. Washington, D.C.: Pan American Health Organization.

Merrell, K. W., \& Popinga, M. R. (1994). The alliance of adaptive behavior and social competence: An examination of relationships between the scales of independent behavior and the social skills rating system. Research in Developmental Disabilities, 15(1), 39-47. doi: 10.1016/0891-4222(94)90037-x 
Ministry of Education and Science of Armenia. (2001). Life skills project implementation in the Armenian education system. Yerevan: Ministry of Education and Science of Armenia.

Ministry of Education of Islamic Republic of Iran. (2008). [National report on development of education in the I.R. of Iran with an emphasis on inclusive education a way to the future (Persian)]. Tehran: Bureau of International Scientific Cooperation.

Ministry of Education and Training in Vietnam. (2006). Life skills mapping in Vietnam. Hanoi: National Institute for education strategy and curriculum.

Ministry of Education, Science and Culture of Iceland (2004). National curriculum guide for compulsory school. Life skills. Reykjavik: Ministry of Education, Science and Culture.

National Center on Educational Outcomes. (2005). 2005 steps forward in a decade of change. Retrieved from http://www.nceo. info

Odom, S. L., Brantlinger, E., Gersten, R., Horner, R. H., Thompson, B., \& Harris, K. R. (2005). Research in special education: scientific methods and evidence-based practices. Exceptional Children, 71(2), 137-148. doi: 10.1177/001440290507100201

Paraschiv, I., \& Olley, G. (1999). Generalization of social skills: Strategies and results of a training program in problem solving skills. Washington D.C.: ERIC.

Quintana, A. (2004). Efficacy of a social skills training procedure used on a child having moderate intellectual disabilities. In J. A. Mulick (Ed.), Handbook of Intellectual and Developmental Disabilities (pp. 601-18). Berlin: Springer.

Shahim, S. (1999). Correlations between parents and teachers' ratings of social skills for a group of developmentally disabled children in Iran. Psychological Reports, 85(3 Pt 1), 863-6. doi: $10.2466 /$ pr0.1999.85.3.863

Sharma, S. (2003). Measuring life skills of adolescents in a secondary school of Kathmandu: An Experience. Kathmandu University Medical Journal, 1(3), 170-6. PMID: 16388225

Shoemaker, M. E. (2009).Comparing social skills in children with autistic disorder and pervasive developmental disorder not otherwise specified [MA. thesis]. Baton Rouge: Louisiana State University.

Turner, N. E., Mc Donald, J., \& Somerset, M. (2008). Life skills, mathematical reasoning and critical thinking: A curriculum for the prevention of problem gambling. Journal of Gambling Studies, 24(3), 367-80. doi: 10.1007/s10899-007-9085-1

World Health Organization. (2013). Life skills education in schools. Program on mental health. Division of mental health and prevention of substance abuse. Geneva: World Health Organization.

World Health Organization. (1993). Partners in life skills education. Geneva: World Health Organization.

Van der Oord, S., Van der Meulen, E. M., Prins, P. J. M., Oosterlaan, J., Buitelaar, J. K., \& Emmelkamp, P. M. G. (2005). A psychometric evaluation of the social skills rating system in children with attention deficit hyperactivity disorder. Behaviour Research and Therapy, 43(6), 733-746. doi: 10.1016/j. brat.2004.06.004 
